Especial: Profesores de Estudios Generales Investigan

Dossier: Ignacio Ellacuría: su vida y su labor académica

\title{
Teoría crítica del derecho en Ignacio Ellacuría
}

Recibido: 31 de setiembre de 2019

Aceptado: 31 de enero de 2020

Andrés Molina Araya

Universidad de Costa Rica, Costa Rica andressr29@gmal.com

https://orcid.org/0000-0003-4914-303X

Resumen: El presente trabajo es un esfuerzo por construir una teoría crítica del derecho, a partir del pensamiento de Ignacio Ellacuría. Para ello, dialoga con algunas de las principales categorías teóricas elaboradas por el autor, y se pregunta, cómo estas contribuirían a tal esfuerzo.

Concluyendo, que una teoría crítica del derecho desde Ellacuría constituye una norma abierta, en diálogo y tensionada con las necesidades del proceso histórico; y principalmente, comprometida con la construcción de una sociedad capaz de suplir de las necesidades humanas, que el autor llamó: la civilización del trabajo.

Palabras clave: realidad histórica; civilización del capital; civilización de la pobreza; movimiento de masas; historización; teoría crítica del derecho.

\section{Critical theory of Law in Ignacio Ellacuria.}

\section{(c) (1)(2)}

La Revista Estudios es editada por la Universidad de Costa Rica y se distribuye bajo una Licencia Creative Commons Atribución-NoComercial-CompartirIgual 3.0 Costa Rica. Para más información envíe un mensaje a 


\section{Especial: Profesores de Estudios Generales Investigan}

Summary: This work is an effort to build a critical theory of Law, through the thought of Ignacio Ellacuria. For this, it talks with some of the main theoretical cathegories elaborated by the autor and asks, how would they contribute to such as effort.

Concluding, that a critical theory of law from Ellacuría constitutes an open norm, in dialogue and stressed with the needs of the historical process; and mainly, committed to building a society capable of supplying human needs, which the author called: the civilization of work.

Key words: historical reality; civilization of the capital; civilization of the poverty; mass movement, historization, critical theory of Law.

... la verdad, cuya madre es la historia, émulo del tiempo, depósito de las acciones, testigo de lo pasado, ejemplo y aviso de lo presente, advertencia de lo por venir.

Jorge Luis Borges.

\section{Introducción}

La sociedad latinoamericana vive situaciones de injusticia social, desigualdad y pobreza. Cada vez más, vemos las consecuencias negativas de la relación social que nos rige, el capital, conflictos sociales crecientes, cambio climático, grupos humanos sumido en la miseria, entre otras.

Se vuelve aún más preocupante cuando somos conscientes de que tales acciones se realizan bajo el orden de la legalidad, tratados de libre comercio, acuerdos internacionales, leyes, reglamentos, entre otros; pues pareciera que los hechos más trágicos que enfrenta la humanidad se realizan bajo el auspicio de la racionalidad legal. Salta a la vista, así, la necesidad de construir una teoría del derecho, que atienda las realidades históricas, sin perder de vista la rigurosidad lógica, formal, que debe tener el lenguaje jurídico.

\section{(c) (i) (2)}

La Revista Estudios es editada por la Universidad de Costa Rica y se distribuye bajo una Licencia Creative Commons Atribución-NoComercial-CompartirIgual 3.0 Costa Rica. Para más información envíe un mensaje a 


\section{Especial: Profesores de Estudios Generales Investigan}

Es por ello, que una teoría crítica del derecho debe ser un instrumento, entre otros, que contribuya al acto liberador, y no el medio a través del cual se justifican las relaciones de explotación y desigualdad social. No puede ser posible que el derecho, del cual se presume es el instrumento de justicia entre las personas, haga caso omiso de las inmensas desigualdades y formas de explotación, sino que más bien sea el que posibilite que, pequeños sectores posean inmensas cantidades de riqueza, perpetúe la explotación, la impunidad y permita la libertad de perpetradores de la injusticia. Tal y como sucede con las miles de personas condenadas a vivir en la pobreza, producto de políticas neoliberales.

Esta investigación busca proponer una teoría del derecho que contribuya a modificar las relaciones sociales actuales, en donde la justicia sea aplicable a las mayorías explotadas, un derecho que tenga como objetivo construir una sociedad en la cual haya espacio para todas las personas, donde esté primero la persona antes que las estructuras, donde el capital y su lógica de acumulación no sean los motores de la historia, sino la solidaridad y el que todas las personas tengan lo necesario para vivir, como lo pretendía Ellacuría. Un derecho que contribuya a la construcción de la civilización de la pobreza, que se contrapone a la actual civilización del capital.

Para alcanzar tal cometido, haremos uso de la totalidad del pensamiento de Ellacuría, no solo de lo que este trató como teoría crítica del derecho, sino que se hará una mirada al conjunto de su obra, que nos permita reconstruir y pensar, desde la óptica de los vencidos de la historia. Es por ello que se indagarán planteamientos éticos, epistemológicos, antropológicos y jurídicos de la propuesta filosófica ellacuriana, que contribuyen a su planteamiento crítico del derecho

\section{La tradición del derecho a partir de Hans Kelsen}

\section{(C) $(00$}

La Revista Estudios es editada por la Universidad de Costa Rica y se distribuye bajo una Licencia Creative Commons Atribución-NoComercial-CompartirIgual 3.0 Costa Rica. Para más información envíe un mensaje a 
Especial: Profesores de Estudios Generales Investigan

Quizá uno de los pensadores que ha tenido una mayor influencia en los sistemas jurídicos que nos rigen haya sido el jurista austriaco Hans Kelsen, por ello, si se desea realizar un planteamiento diferente del derecho, es necesario empezar por hacer una referencia al mismo. Para Kelsen, el derecho es "un mal necesario en el mejor de los casos" (Contreras, 1989a, p.30), pues, las personas al ser seres sociales vivimos necesariamente en sociedad; proceso que se ve mediado por conflictos, situación que hace necesitar normas que regulen dicha convivencia. Y continúa, "en la línea de Freud, Kelsen pensó al hombre como un ser cuya naturaleza más recóndita incluyera pulsiones egoístas, violentas y anticomunitarias" (Contreras, 1989a, p.30), el derecho sería el instrumento por medio del cual la represión, el control social y la tolerancia democrática permiten a las personas vivir en sociedad (Contreras, 1989a); esto hace de Kelsen un pesimista de la naturaleza humana, un defensor del derecho como medio para la subsistencia social; en la misma dirección que fundamentó Hobbes el origen del Estado, como el instrumento que permite vivir en sociedad a las personas sin matarse entre sí.

Menciona Mario Ruiz Sanz (2002), para referirse al sistema del derecho de Kelsen, que:

... un sistema jurídico se compone exclusivamente de un conjunto de normas cuyo fundamento último es una norma presupuesta que garantiza la unidad y validez de todo el sistema. A la vez, su pretensión cientificista le hace partir de la idea de que el Derecho debe aparecer exento de contradicciones, porque así lo exige la propia ciencia jurídica. Para este autor, la coherencia lógica es una condición esencial del ordenamiento jurídico, puesto que la posible existencia de antinomias jurídicas es un problema más bien aparente. El Derecho es un sistema dinámico en el que las normas inferiores derivan su validez de otras superiores y competentes para autorizar formalmente su vigencia, y de esta manera el ordenamiento jurídico acaba por conformar una estructura piramidal en la que por definición no pueden existir antinomias o contradicciones normativas. (Ruiz, 2002, p.17)

\section{(C) $(\Theta \odot$}

La Revista Estudios es editada por la Universidad de Costa Rica y se distribuye bajo una Licencia Creative Commons Atribución-NoComercial-CompartirIgual 3.0 Costa Rica. Para más información envíe un mensaje a 
Especial: Profesores de Estudios Generales Investigan

Esta referencia nos permite ver algunos de los elementos centrales y más característicos de la obra de Kelsen.

El sistema jurídico es un conjunto de normas en donde su validez la garantiza la concordancia de una norma inferior con la norma fundamental o primera; por ello, "todo posible conflicto que se diera en el Derecho debería ser resoluble dentro del propio sistema" (Ruiz, 2002, p.19), su planteamiento es un sistema cerrado, lógico en sí mismo, y que se resuelve desde la concordancia, o no, de una norma con relación de la que emana, explicita o procede.

Es así que la ausencia de contradicción en la norma es sinónimo de cientificidad; ya que, si una norma carece de coherencia lógica e interna, no hay concordancia con la norma fundamental, pierde validez y no podría ser considerada como cierta, "la resolución de los conflictos normativos es de carácter intrasistémico, ya que todo conflicto debe ser resuelto en el marco del sistema jurídico" (Ruiz, 2002, p.24).

Las antinomias en un sistema jurídico no tendrían razón de ser, pues ello indicaría que el sistema jurídico tiene una inapropiada interpretación de la norma fundamental; es por ello que el sistema jurídico es presentado como una perfecta organización piramidal, en donde toda norma inferior debe encontrar una correlación lógica con aquella de la cual procede.

Esta es la interpretación tradicional que se hace de la obra de Kelsen, su intento por formular un derecho lógico y valido en sí mismo; es lo que se conoce como teoría tradicional, en donde "se puede considerar al derecho como una normatividad de carácter universal, absoluto, abstracta, ahistórica, no dialéctica y acultural" (Senent de Frutos, 2013, p.61).

A tenor de lo anterior, Oscar Contreras menciona que lo planteado por Kelsen ha sido mal interpretado por los iusnaturalistas, que justifican un poder político a través del derecho so pretexto del bien común, justificándose un sistema de dominación en beneficio de un sector, "justamente aquel cuyo contenido

\section{(c) (i) (-)}

La Revista Estudios es editada por la Universidad de Costa Rica y se distribuye bajo una Licencia Creative Commons Atribución-NoComercial-CompartirIgual 3.0 Costa Rica. Para más información envíe un mensaje a 


\section{Especial: Profesores de Estudios Generales Investigan}

coincide con la particular concepción del iusnaturalismo de que se trata" (Contreras, 1989b, p.10); dicha concepción puede ser de múltiples concepciones: católica, nazi, de empresarios y empresarias (Contreras, 1989b); tal construcción es hegemónica, pues hace ver el interés de un sector como el interés general, de forma que el poder se oculta tras el derecho y su presunción de universalidad. En tono hilarante, Oscar Contreras afirma: "nomás hay que ver cómo 'las gastan' cuando tienen el poder, para tener una confirmación de lo mucho que aprecian su justicia" (Contreras, 1989b, p.10).

Ante esta realidad, la construcción del derecho tocado por un centro político del poder, una verdad que se fabrica y que se nos impone, afirma Contreras (1989b): Lo que Kelsen hace, frente a ello, es politizar el contenido de la justicia: lo único justo es que todos tienen el derecho a proponer su concepción de lo justo en la arena política; y el que convenza a más conciudadanos debe disponer del poder mientras mantenga el consenso para su gobierno (p. 10).

Es la necesidad de poner en la discusión política las diferentes posiciones de lo justo y de lo que debe plantearse por derecho, y después de esto, lo que la mayoría acepte, se construye la norma para regir las relaciones sociales y gobernar.

Es decir, la pretensión de Kelsen es fundar una teoría pura del derecho, que pueda evitar que poderes mediáticos pasen por ciencia sus propios intereses, es por ello que: "la razón para fundar una ciencia pura del derecho no consiste en justificar todo poder, sino en lo contrario: despojar de toda justificación "científica" a cualquier poder" (Contreras, 1989a, p.28).

Ya sea desde la lectura tradicional de Kelsen, de tomar su obra como un sistema cerrado, racional y lógico en sí mismo, que explica la validez desde la concordancia interna de las normas; o sea visto como ese pensador que intentó fundar una filosofía del derecho que evitara ser usada en los avatares del poder y legitimaciones de Estado. Una y otra forma, sin hacer desmérito de lo mucho que

\section{(C) $(\Theta \odot$}

La Revista Estudios es editada por la Universidad de Costa Rica y se distribuye bajo una Licencia Creative Commons Atribución-NoComercial-CompartirIgual 3.0 Costa Rica. Para más información envíe un mensaje a 


\section{Especial: Profesores de Estudios Generales Investigan}

pueden aportar, son sistemas centrados en la razón y que atienden poco a la realidad histórica y sus necesidades reales.

El reto está en platear una construcción del derecho que dé cuenta de las particularidades históricas, que busque la rigurosidad lógica sin hacer abstracción de la realidad.

El meollo con el derecho radica en que toda formulación que del mismo se haga en es situada, culpable, es tributaria de un proceso, aunque se presente como transhistórico, perenne y de carácter universal. Ninguna formulación de una norma puede abstraerse de las condiciones históricas, sociales, estéticas, ideológicas, culturales y circunstanciales que le dieron origen.

Para construir una propuesta alternativa del derecho, lo primero que debemos hacer es salirnos de las pretensiones de universalización de un derecho puro, que pretenda abrigar la totalidad de la realidad, cuando la misma es diversa, múltiple y marcada por contradicciones distintas en su género. En este sentido, se presentarán algunas de las reflexiones y aportes desarrollados en el pensamiento de Ignacio Ellacuría.

\section{Civilización del trabajo y teoría crítica del derecho.}

Ellacuría llamó a la sociedad que nos rige "la civilización del capital", en la cual, el capital se ubica sobre las subjetividades y los Estados, y a su vez, denominó a esta relación social “orden histórico” (Ellacuría, 1989b). Así, las abrumadas desigualdades y explotaciones que se viven en el orden global que impera en la sociedad actual no son un producto de la casualidad o del azar, sino de un sistema social e histórico que las produce. A tan solo diez días antes de su asesinato, Ellacuría afirmaba:

Quien impone realmente las leyes de casi todos los procesos, en unos con mayor peso que en otros, es el dinamismo del capital. No es primariamente que los hombres, las clases o grupos sociales, las naciones o los grupos de las naciones hayan decidido ponerse al servicio de la producción y la acumulación del capital;

\section{(c) (i) (2)}

La Revista Estudios es editada por la Universidad de Costa Rica y se distribuye bajo una Licencia Creative Commons Atribución-NoComercial-CompartirIgual 3.0 Costa Rica. Para más información envíe un mensaje a revistaestudios.eeg@ucr.ac.cr. 


\section{Especial: Profesores de Estudios Generales Investigan}

es que el capital, sobre todo en su dimensión internacional, pero también nacional, pone a su servicio a los hombres, a las clases sociales, a las naciones y ya no digamos a todo el aparato económico, que es la parte más determinante del organismo social (Ellacuría, 1989a, p.357).

Y según Ellacuría, la civilización del capital está conduciendo a nuestras sociedades a: a) una amplia brecha entre ricos y podres, b) un endurecimiento de los procesos de explotación y opresión con formas más sofisticadas, c) no solo al desglosamiento ecológico progresivo de la totalidad del planeta, d) sino a la deshumanización de quienes se niegan a construir su ser bajo las atrocidades del tener, la acumulación de la riqueza, el poder, honor y la más cambiante gama de bienes consumibles (Ellacuría, 1989a).

Ahora bien, si la civilización del capital es el marco general de la sociedad actual y, por ende, de todo derecho o normativa que se construya, ¿cómo pensar un derecho que no contribuya a la civilización del capital?, cómo alejarnos de la visión pesimista antropológica que planteaba Kelsen, de ver el derecho como la forma coercitiva que permite la vivencia en sociedad, pues las personas somos egoístas por naturaleza.

Es necesario salirse de la lógica capitalista y lanzarse a la construcción de otro tipo de sociedad, permitirnos volver a soñar, aprender del pasado y volvernos a plantear una sociedad que resuelva la fractura estructural que nos afecta: la contradicción capital-trabajo; y así preguntarnos ¿cómo construir una sociedad donde no se den esos excesos y riesgos a los que nos ha llevado la civilización del capital?

Para poder ensayar una respuesta a estas preguntas -ya que quien solo podrá otorgarles una resolución satisfactoria será la praxis-, se debe iniciar por señalar que solo en la medida que operemos el origen estructural de conflicto, es decir, la lógica de acumulación de capital, podremos empezar a construir una

\section{(C) $(00$}

La Revista Estudios es editada por la Universidad de Costa Rica y se distribuye bajo una Licencia Creative Commons Atribución-NoComercial-CompartirIgual 3.0 Costa Rica. Para más información envíe un mensaje a 
Especial: Profesores de Estudios Generales Investigan

posible salida del conflicto; pues el verdadero mal de nuestras sociedades radica en que la acumulación de capital es el motor de la historia.

Como señala Habermas (1997), el derecho moderno es formal, individualista y coercitivo. Pero, en un contexto distinto a la sociedad moderna capitalista, en la civilización del trabajo que apunta Ellacuría, estos no podrían ser los fines del derecho, pues, antes que prohibir, lo que pretendería es generar las condiciones sociales e históricas para que las personas, una vez resueltas sus necesidades de reproducción (vivienda, alimento, recreación, etc.), puedan elegir libremente lo que desean hacer en sus vidas; ya que en una sociedad, en la que las personas puedan resolver sus necesidades de subsistencia -cosa que no sucede en la sociedad del capital a las mayorías empobrecidas, actualmente-, se podrá elegir, auténticamente lo que se desea hacer con el rumbo de la propia existencia.

Esto no elimina las responsabilidades individuales, o la necesidad de normas y leyes, sino que traslada el objeto principal del derecho a la distribución de la riqueza. En buena medida, sería una radicalización del derecho, pues legislaría sobre la acumulación excesiva de capital, de manera tal, que se garanticen condiciones suficientes para todas las personas. Como el propio Ellacuría sostuvo de la caracterización de una sociedad liberada, en la "que cada uno sea, tenga y se le dé, no lo que se supone que ya es suyo porque lo posee, sino lo que le es debido por su condición de persona humana y por su condición de socio de una determinada comunidad" (Ellacuría, 1993, p.15). Es decir, una teoría crítica del derecho, buscaría por norma general, garantizar las condiciones necesarias a las personas, por el hecho de ser parte de una sociedad, por su ser persona.

\section{(C) $(00$}

La Revista Estudios es editada por la Universidad de Costa Rica y se distribuye bajo una Licencia Creative Commons Atribución-NoComercial-CompartirIgual 3.0 Costa Rica. Para más información envíe un mensaje a 


\section{Especial: Profesores de Estudios Generales Investigan}

Vendría a ser una sociedad que otorga los derechos individuales, porque antes ha garantizado los sociales; afirmando así que es necesario "que todos sean libres para que cada uno pueda serlo" (Ellacuría, 1993, p.11), deja de lado la concepción individualista de la sociedad actual, en donde mi libertad termina en donde empieza la de la otra persona, idea que se despreocupa de los ideales colectivos y solidarios característicos de la civilización del trabajo.

Vendría a ser además, una sociedad que otorga los derechos individuales, porque antes ha garantizado los sociales, pues es necesario "que todos sean libres para que cada uno pueda serlo" (Ellacuría, 1993, p.11), esta concepción de libertad -de la que participaría una teoría crítica del derecho- elaborada por Ellacuría, no sólo deja de lado la concepción individualista de la civilización del capital, en donde mi libertad termina en donde empieza la de la otra persona, sino que la supera, pues rescata la individualidad al procurar el bien general; o lo que es lo mismo, reconoce que sólo una sociedad que garantice la satisfacción de las necesidades de todas las personas, podrá hacer posible una individualidad libre, y capaz de autorrealizarse.

Ahora bien, lo anterior no elimina la existencia de coerción y penas en una teoría crítica del derecho, sólo las ubica bajo circunstancias espaciotemporales, según las necesidades de cada caso en concreto (Estado o formación social), buscando un fin colectivo, no de represión y de control social para reproducir la acumulación de capital, sino que sancionaría a aquellas personas o grupos que lesionen o dañen lo que la propia sociedad ha señalado como proyecto colectivo, o sociedad común. Lo principal que una teoría crítica del derecho debería sancionar sería la acumulación de capital de sectores privados, y lo segundo, el beneficio individual de los funcionarios de los aparatos públicos, burocracias, que operando lo público se enriquecen a costa de lo que debe ser colectivo. Debería además prohibir la mercantilización de sectores esenciales para la vida de las personas, tales como la salud y la educación. Debe buscar como regla general el 


\section{Especial: Profesores de Estudios Generales Investigan}

desarrollo en cultura, arte e historia de las personas que integran la sociedad de la que forman parte, para que así, puedan tomar decisiones conociendo el alcance de las mismas. A su vez, debe garantizar un verdadero y auténtico respeto de la libertad de expresión, prohibiendo la instrumentalización de la prensa a intereses corporativos y de acumulación de riqueza, por eso, debe regular la concentración de medios de información y corporativización de la prensa, porque la libertad de expresión se violenta, no sólo desde los Estados, sino que también desde lo privado.

Ahora bien, los fundamentos de una teoría crítica del derecho, tanto en lo que se prohíbe, sanciona o se promueva, debe estar alejado de ensoñaciones idealistas, sino por el contrario, profundamente marcado por las necesidades concretas de la sociedad que lo promulga. $\mathrm{Y}$ dos categorías del pensamiento de Ellacuría nos pueden ayudar en esta dirección: a) la filosofía como "labor concreta", no abstracta y ahistórica (Ellacuría, 1991, p.108), y b) la historia como "lugar-que-da-verdad y la hace verdad" (Ellacuría, 1991, p.115). Pues para Ellacuría el pensamiento debe ser situado, no dicho de forma universal y ahistórica, sino que debe dar cuenta de las necesidades para las que se afirma. $Y$ además, al ser historizado, puesto en la práctica, se convierte en momento de verdad, es decir, somete a prueba lo que observó y pensó de la realidad. Este es quizá uno de los principales aportes de la categoría "historización" de Ellacuría, pues el proceso de construcción de la "civilización de trabajo" -historizar la teoríano obedece únicamente a un imperativo moral por procurar una sociedad más justa, sino que además confirma, niega o corrige la teoría, pues al llevar a la práctica lo teorizado, se contrasta en qué medida tiene verdad lo pensado.

Por ello, teoría crítica del derecho y civilización del trabajo, en Ignacio Ellacuría no pueden ser dos procesos independientes y separados, sino dos momentos de un mismo proceso. Pues el derecho formula una norma, que parte

\section{(c) (i) (-)}

La Revista Estudios es editada por la Universidad de Costa Rica y se distribuye bajo una Licencia Creative Commons Atribución-NoComercial-CompartirIgual 3.0 Costa Rica. Para más información envíe un mensaje a 


\section{Especial: Profesores de Estudios Generales Investigan}

de necesidades concretas -historizadas-, y de un proyecto político claro -la civilización del trabajo-, que luego lleva a la práctica para conocer qué tanto de lo pretendido por la norma tuvo verdad o cumplió lo pretendido. Y una vez realizado este proceso, se repite el mismo, incorporando los aprendizajes obtenidos como producto de la historización de la norma. En términos ellacurianos, la civilización del trabaja, sería el-lugar-que-da-verdad a una teoría crítica del derecho

Y a lo anterior, debemos agregar otra categoría usada por Ellacuría como lugar-que-da-verdad, a saber: "movimiento de masas". Al igual que la civilización del trabajo, el movimiento de masas se convierte en un concreto que confirma 0 niega la teoría, y por ende, un espacio que debe ser tomado en cuenta por una teoría crítica del derecho. Afirma Ellacuría: "ya que esa organización de las masas y ese movimiento popular debería ser la auténtica fuerza social que controlase el poder político sin pretender convertirse en un poder político que controlase a la fuerza social" (Ellacuría, 1987, p.784). Una propuesta crítica del derecho debe partir de las bases de la sociedad, de las mayorías excluidas, de las personas pobres y excluidas, ellas son quienes deciden, por mecanismos de toma de decisión colectivos, cuáles pueden ser los fundamentos de una teoría crítica del derecho. Nunca pueden ser sectores hegemónicos, que desoyendo a las mayorías empobrecidas, formulen las normas de una sociedad.

Es por ello, que en la consolidación y conformación de las masas, se podrá encontrar otro concreto que ayude a formular una teoría crítica del derecho, pues dirá Ellacuría, son ellas mismas las que deciden "autónomamente cuáles deben ser su estrategia y sus tácticas, así como sus alianzas" (Ellacuría, 1987, p.790). Pues ellas fungen como catalizador de sus necesidades, y por ello, deben determinar a su ritmo, y a su modo, lo que quieren ser y lo que quieren hacer (Ellacuría, 1987). Atender movimientos de masas, como podrían ser los ecologistas, de mujeres, Occupy Wall Street, entre otros, permite formular una

\section{(c) (i) (2)}

La Revista Estudios es editada por la Universidad de Costa Rica y se distribuye bajo una Licencia Creative Commons Atribución-NoComercial-CompartirIgual 3.0 Costa Rica. Para más información envíe un mensaje a 


\section{Especial: Profesores de Estudios Generales Investigan}

teoría del derecho -que sin perder de vista la formalidad de la norma- se preocupa por responder a necesidades históricamente existentes. Y más aún, se pregunta, qué de la formulación actual del derecho no está respondiendo a las necesidades de las sociedades actuales, que se propician tales movimientos.

Por eso, afirma Juan Antonio Senent de Frutos:

... lo que la teoría tradicional pretende de diversos modos, según las corrientes doctrinales, es separar el momento normativo de la praxis en la que acontece, estableciendo así un hiato o ruptura entre los sentidos normativos y la praxis. Lo normativo se presentaría entonces como una instancia trascendente a la propia praxis y no con un carácter inmanente y abierto, que es como la línea crítica trata de considerarla en cuanto el derecho es para la sociedad y recreado y reapropiado desde la sociedad. (Senent de Frutos, 2013, p.63)

Es por ello, que una teoría crítica del derecho a partir de Ignacio Ellacuría trastoca las bases de la sociedad actual, si bien, toma elementos que el propio capitalismo ha producido, pues muchos de ellos tienen verdad -la tecnología, la secularización del mundo, la libertad individual, etc.-, transmuta su fin fundamental: la acumulación de capital. Su realización, pasa por construcción de la civilización del trabajo, que no es más que el proyecto de los pobres y oprimidos del mundo por "revertir la historia, subvertirla y lanzarla en otra dirección" (Ribera, 2013, p.42). Por ello, Ignacio Ellacurría afirmará, nuestro proyecto histórico parte "desde la negación profética y desde la afirmación utópica, apunta hacia un proceso de cambio revolucionario, consistente en revertir el signo principal que configura la civilización mundial” (Ellacuría, 1989a, p.357). De ese proyecto histórico, anunciado por Ellacuría, forma parte una teoría crítica del derecho.

\section{(C) $(0 \bigcirc$}

La Revista Estudios es editada por la Universidad de Costa Rica y se distribuye bajo una Licencia Creative Commons Atribución-NoComercial-CompartirIgual 3.0 Costa Rica. Para más información envíe un mensaje a 
Especial: Profesores de Estudios Generales Investigan

\section{Teoría y praxis en el pensamiento de Ellacuría}

Sin lugar a dudas, existe dificultad al pensar la relación entre la teoría y la praxis, pues con mucha facilidad una prescinde de la otra. Por ello, para entender el pensamiento de Ignacio Ellacuría se debe prestar atención al nuevo concepto de realidad e inteligencia que usa, que le alejan de reducciones dualistas (Samour, 2001), en las que se ha visto envuelto gran parte del pensamiento occidental desde tiempos de Parménides; lo que Ellacuría llamó como la logificación de la inteligencia y la entificación de la realidad; en donde sin inteligencia-logos- no se pueden acceder a la realidad, y la realidad, en virtud de esto, se cierra, encapsula en sí misma, convirtiéndose en incomunicable.

¿Dónde se encuentra el origen de dicho problema de la separación entre inteligencia y realidad? Ellacuría menciona que en la separación entre sentir y pensar, se origina cuando Parménides afirma que "inteligir algo es inteligir qué es" (Ellacuría, 1989b, p.2); esto hace de la inteligencia la capacidad afirmativa, la facultad sine qua non que nos permite acceder a la realidad, en virtud de la cual puedo conocer el ser de las cosas, en razón de su racionalidad y lógica interna (Samour, 2001). Dicho de distinta forma, sin conocimiento no podemos acceder a la realidad.

A lo anterior, Ellacuría propondrá que acceden a la realidad todas las personas en virtud de percibir lo real en cuanto real; el conocimiento, por su parte, lo que permite es la profundización de la realidad.

Esta intuición pone a todas las personas en la realidad, solo que en distintos niveles de comprensión de la misma; es por ello que Zubiri, quien fuera en estos temas el maestro de Ellacuría, llamará a las personas animales de realidad, pues lo que diferencia a las personas de las demás formas de realidad es la capacidad de percibir lo real como real y no como un estímulo (Ramírez, 2002); todas las personas estamos desde distintas aristas accediendo a la realidad, más estamos realmente en la realidad.

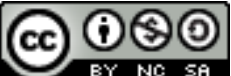

La Revista Estudios es editada por la Universidad de Costa Rica y se distribuye bajo una Licencia Creative Commons Atribución-NoComercial-CompartirIgual 3.0 Costa Rica. Para más información envíe un mensaje a revistaestudios.eeg@ucr.ac.cr. 

y, de esta forma, comprender la categoría realidad histórica, nos dirá Hector Samour:

En la visión zubiriana, el sentir humano y el inteligir no solo no se oponen, sino que se constituyen en su intrínseca y formal unidad en un solo y único acto de aprehensión de realidad. No se trata de una mera continuidad entre sentir e inteligir, ni de una unidad en el sentido de que ambas versarán sobre el mismo objeto, sino de una unidad estructural y sistemática. Para Zubiri, la aprehensión de realidad arranca con el proceso sentiente del animal humano, pero aquí no hay distinción o dualidad entre sensibilidad y aprehensión de realidad o intelección. [...] Lo que hay en realidad es un único acto, un solo proceso unitario que Zubiri denomina aprehensión sintiente de realidad. (Samour, 2001, pp.4-5).

Esta relación entre el sentir e inteligir es lo que le servirá a Ellacuría para explicar la relación entre teoría y praxis. El sentir la praxis como una realidad real nos lleva a inteligirla y profundizarla más por medio de la razón, sin llegar a una separación entre teoría y praxis, sino que la teoría es un momento de la praxis (Senent de Frutos, 2013), el acto de su mayor comprensión y profundización. Además, como parte de la intelección de la realidad y su mayor profundización se encuentra la desideologización, pues la realidad es falseada por la ideología (Ellacuría, 1991).

Este ser, un animal de realidades, como le llama Zubiri, trae una serie de implicaciones, pues nos hace a todas las personas conocedoras, perceptoras de la realidad; de forma que, si se le pregunta a una persona en condición de pobreza por su realidad de vida, esta, aunque sin teoría para explicar lo que le está sucediendo, tiene un conocimiento cierto y más real de la situación de pobreza que el que vive en una condición de bienestar o pertenece a una clase social alta; esto hace más conocedores de la realidad real (en el caso de América Latina Ellacuría señalaba que era de pobreza) a las personas en exclusión que a las personas que concentran la riqueza.

\section{(c) (i) (2)}

La Revista Estudios es editada por la Universidad de Costa Rica y se distribuye bajo una Licencia Creative Commons Atribución-NoComercial-CompartirIgual 3.0 Costa Rica. Para más información envíe un mensaje a 


\section{Especial: Profesores de Estudios Generales Investigan}

En los siguientes términos se refiere Ellacuría a la teoría y la praxis en relación con el derecho:

Este proceso dialéctico debe poner en marcha su dialecticidad en la teoría y en la praxis: en la teoría para descubrir, por negación superadora, cuál es el rostro histórico del derecho deseable y posible; en la práctica para lograr que la lucha por la realización del derecho consiga que se haga justicia y llegue a anular, no necesariamente a aniquilar, la realidad negadora en lo que tiene de negadora. (Ellacuría, 1999b, p.438)

No es de Perogrullo afirmar que la dialéctica se da en la relación de la teoría y la praxis, entre la afirmación de la teoría y negación de la praxis; lo importante de resaltar a acá es que no se produce un hiato entre teoría y praxis, sino que la teoría se presenta como un momento de la praxis, no como dos realidades ajenas una de la otra, sino como dos momentos del mismo proceso.

\section{Realidad histórica como objeto de la filosofía y lugar de verdad}

Una de las categorías centrales en la obra y el pensamiento de Ignacio Ellacuría es realidad histórica. Resulta imperioso referirse a ella si lo que se quiere es construir una propuesta crítica del derecho a partir de la obra académica.

Cinco son las características que distinguen a la realidad histórica, a saber:

a) "Es una sola unidad física compleja y diferenciada, de modo que ni la unidad anula las diferencias ni las diferencias anulan la unidad" (Ellacuría, 1999b, p.31). La realidad en cuanto es real es transcendental, intrínsecamente y constitutivamente respectiva; es decir, las cosas están en relación y correspondencia mutua, en cuanto poseen unidad.

b) "Es intrínsecamente dinámica, de modo que la pregunta por el origen del movimiento es o una falsa pregunta 0 , al menos, una pregunta secundaria" (Ellacuría, 1999b, p.33); el tipo de dinamismo corresponderá al tipo de realidad; formalmente ese dinamismo es dar de sí, en el entendido que es un desdoblamiento del sí mismo de las cosas y lo que puede dar, aunque nunca sin perder el sí mismo que es producto de la unidad de la realidad; es sin lugar a 


\section{Especial: Profesores de Estudios Generales Investigan}

dudas un cambio superador de aquello que siendo siempre el sí mismo, nunca es lo mismo (Ellacuría, 1999a). En razón de la respectividad de las cosas, producto de su unidad, y en el entendido de que la realidad intramundana es dinámica, surge de esta manera la funcionalidad de las cosas entre sí, en cuando reales, interactuando entre ellas, propiciando de esta manera subsistemas entre las cosas, cuyos componentes son más unitarios entre sí y se diferencian de otros subsistemas, aunque todos sean parte un mismo sistema (Ellacuría, 1999a).

c) “El carácter no universalmente dialéctico. La realidad siendo en sí misma sistemática, estructural y unitaria, no es necesariamente dialéctica o, al menos, no es unívocamente dialéctica" (Ellacuría, 1999b, p.35). Lo específico y formal de la realidad histórica no solo está en la aceptación de la existencia de la contradicción de las cosas, sino en la predominancia de la negación tanto en lo referente al movimiento como a la unidad (Ellacuría, 1999a).

d) "El carácter procesual y ascendente de la realidad" (Ellacuría, 1999b, p.38). Es decir, "la realidad no solo forma una totalidad dinámica, estructural y, en algún modo, dialéctica, sino que es un proceso de realización, en el cual se van dando cada vez formas más altas de realidad, que retienen las anteriores, elevándolas" (Ellacuría, 1999b, p.38). La realidad en tanto se muestra dando de sí, propiciando de esta manera, formas superiores de realidad, en donde las superiores se apoyan de las que proceden y estas se hacen presentes en aquellas (Ellacuría, 1999a). Ellacuría divide la realidad en cinco diferentes formas: la materia, la vida, la animalidad, la realidad humana y la realidad social e histórica. De esta forma, podemos hablar de grados de realidad, en tanto que una planta tiene más realidad que una piedra, y es a su vez "otra forma de realidad posterior y superior" (Ellacuría, 1999b, p.40)

e) "La realidad histórica como objeto de la filosofía" (Ellacuría, 1999b, p.42). En decir, "la 'realidad histórica' es el 'objeto último' de la filosofía, entendida como metafísica intramundana, no solo por su carácter englobante y totalizador, sino en

\section{(C) $(00)$}

La Revista Estudios es editada por la Universidad de Costa Rica y se distribuye bajo una Licencia Creative Commons Atribución-NoComercial-CompartirIgual 3.0 Costa Rica. Para más información envíe un mensaje a 
Especial: Profesores de Estudios Generales Investigan

cuanto manifestación suprema de realidad" (Ellacuría, 1999b, p.42). La realidad histórica es "donde se da la mayor densidad de lo real” (Ellacuría, 1999b, p.42), donde la realidad es más, más suya y más abierta.

Es por ello que la filosofía ha de atender la realidad histórica para entender la verdad de lo real. Se entiende por demás la importancia tan grande que da Ellacuría a la historización de las teorías, ya que es poner en el lugar de mayor densidad de lo real lo que la realidad humana ha inteligido de la realidad histórica; es depositar o devolver a la realidad histórica lo que se ha pensado a partir de ella.

Es así que una propuesta crítica del derecho debe partir de las necesidades de la realidad histórica como "maestra de la verdad" (Romero Cuevas, 2013, p.65), y es ella, en el momento que se pone en práctica lo pensado, la que podrá decir qué tanta verdad puede tener la norma formulada. Una teoría crítica del derecho en Ellacuría se construye en constante diálogo con la realidad histórica. Para su formulación parte de la realidad histórica, piensa a partir a ella, y una vez formulada la norma, la devuelve a la realidad histórica, para que sea esta, como maestra de verdad, la que arrogue cuánto de verdad puede existir en dicha norma.

Este acento en la realidad histórica, como grado superior de realidad y maestra de verdad, tiene otra importante característica: desideologizar. Bien es conocido el carácter hegemónico que tienen las sociedades actuales, que ubica el interés de un sector -capital- como el interés general, haciendo pasar la parte por el todo. Esto es lo que usualmente hace la teoría tradicional del derecho, aprobar leyes y normativas que benefician abiertamente a un sector de la sociedad y perjudican a las mayorías empobrecidas, pero sostenidas como interés general. Por esto, el tratar de construir una teoría crítica del derecho, en donde la realidad histórica sea la que otorgue el carácter de verdad a la norma, ayudará a poner en evidencia el carácter de universalidad que pueda tener la misma. Como afirma el propio Ignacio Ellacuría:

El movimiento teórico implica volverse a la historia presente de un modo crítico, para delimitar fuerzas y acción, tanto liberadoras como dominadoras; se elige la

\section{(c) (i) (2)}

La Revista Estudios es editada por la Universidad de Costa Rica y se distribuye bajo una Licencia Creative Commons Atribución-NoComercial-CompartirIgual 3.0 Costa Rica. Para más información envíe un mensaje a revistaestudios.eeg@ucr.ac.cr. 
Especial: Profesores de Estudios Generales Investigan

perspectiva de la liberación no solo por lo que tiene de tarea ética como lugar privilegiado de realidad y de realización del hombre y de la humanidad, sino por lo que tiene de potencialidad teórica, tanto en la fase creativa como en la fase crítica desideologizadora. (Ellacuría,1991, p.115)

Esta centralidad de la realidad histórica se convierte en una especie de campo de prueba de la teoría, que dejaría en evidencia aquellos esfuerzos normativos que, afirmados con presunción de universalidad, no son más que intereses de un sector de la sociedad, disfrazados de interés general.

\section{Historización del derecho}

¿Qué debemos entender cuando usamos la categoría historización de conceptos en la obra de Ellacuría? Él mismo lo aclara de la siguiente manera: "La historización consiste, entonces, en probar cómo se da, en una realidad histórica determinada, lo que formalmente se presenta como bien común y como derechos humanos, y en mostrar cuáles son los mecanismos por los cuales se impide o se fortalece la realización efectiva del bien común” (2001, p.219).

Así, el derecho y las normas que rigen a todas las personas de una sociedad tienen que pretender el bien común, lo cual no es tanto una categoría universal a priori, sino común en el tanto que realmente existe en cada una de las personas, pues "el bien común solo es realmente común si propicia un tipo de vida común" (Ellacuría, 2001, p.218).

Dicho esto, "lo importante en el proceso de historización no es el logro alcanzado en un momento determinado, sino la orientación del proceso. Pero no su orientación ideal, sino su orientación real” (Ellacuría, 2001, p.219). Por ello, cuando hablamos de una teoría crítica del derecho, no debe pensarse en término de ortodoxia, sino de una ortopraxis. Su propósito es orientar el proceso de conformación del derecho, a partir de las necesidades realmente existentes.

De esta forma, la historización se convierte en la orientación real del derecho, en donde no será la coherencia interna de la norma la productora de

La Revista Estudios es editada por la Universidad de Costa Rica y se distribuye bajo una Licencia Creative Commons Atribución-NoComercial-CompartirIgual 3.0 Costa Rica. Para más información envíe un mensaje a 


\section{Especial: Profesores de Estudios Generales Investigan}

justificación, ni los ideales de justicia y bien en general, sino el haber sido pensada a partir de necesidades concretas y luego sometida a prueba en el proceso sociohistórico de la realidad histórica como maestra de verdad.

Esto impedirá que el bien común sea pervertido, lo cual sería "la apropiación privada de lo que es común, la negación de lo común en beneficio de lo que es particular, la anulación del todo estructural en beneficio de algunas partes disgregadoras de ese todo" (Ellacuría, 2001, p.213). Esto tiene un profundo valor antihegemónico, pues sería un mecanismo que pondría en evidencia a los grupos de poder de una sociedad, que usando el derecho, y haciéndolo ver como interés general, deslizan tras el mismo los intereses propios.

Para lograr tales pretensiones "«hay que desprivatizar la ética», trascendiendo así el ámbito de lo privado (la familia, el trabajo, el consumo)" (Cascante, 2003, p.66), es decir, los actos políticos, económicos y normativos deben estar dentro de un marco ético, y por ello se entiende: que puedan ser universalizables ${ }^{1}$, de lo contrario no podrían considerase como tales, "así resulta que la justicia, como puesto en marcha del bien común, es la virtud fundamental de la ciudad y es el norte orientador del ciudadano y del político" (Ellacuría, 2001, p.214).

El momento de la justicia dentro del proceso de historización del derecho es crítico, racional y ético. Es racional porque se trata de una norma producto de la praxis humana, en función del interés -históricamente existente- de todas las personas, y no de unas cuantas y su afán de acumular capital; es crítico porque problematiza las necesidades reales, existentes y se plantean, por medio de la norma, buscar una superación de las mismas. Tal y como el propio Ellacuría lo afirma, "hace falta a la vez una actitud ética y una actitud crítica; solo en la conjunción de ambas uno se puede ir acercando paulatinamente a la verdad,

\section{(C) $(00$}

La Revista Estudios es editada por la Universidad de Costa Rica y se distribuye bajo una Licencia Creative Commons Atribución-NoComercial-CompartirIgual 3.0 Costa Rica. Para más información envíe un mensaje a 
Especial: Profesores de Estudios Generales Investigan

sobre todo en el terreno donde están más comprometidos los intereses humanos" (Ellacuría, 1976, p.589).

La desprivatización de la ética y la criticidad a la sociedad son una praxis racional, en donde la lectura de los hechos políticos, la desideologización, el desenmascaramiento del funcionamiento del sistema son una labor liberadora de la filosofía “... antes reconstruyéndose como tal, ser realmente eficaz a la hora de liberar no a unas pocas élites ilustradas, sino a la totalidad de la cultura y a la totalidad de las estructuras sociales, dentro de las cuales las personas tienen que autorealizarse libremente (Ellacuría, 1991, p.95).

Esta tarea, aunque se realiza en el movimiento social, en las bases de la sociedad, es una labor acuciosa y delicada, y requiere de amplia erudición; no debemos olvidar que para Ellacuría la teoría no se encuentra fuera de la praxis, sino que es praxis misma.

Cuando se dice que el derecho debe ser construido desde la realidad, en contacto con ella, no se trata de una acción no teórica, sino una acción meticulosamente pensada, pero a partir de las necesidades históricas, pues estas son las que otorgan los ajustes o desajustes, que según Juan Antonio Senent(2013) "remite a la necesidad de que el derecho vivido sea factible entre los demás y uno mismo y entre el conjunto de lo real y los sujetos de las prácticas" (2013, p.70). Además, partir de las necesidades históricas ayuda a no forzar la realidad, lo que es lo mismo, pensar a partir de una "posibilidad real" (Valls Plana, 1981, p.134), el deber ser, la norma que se construye a partir de necesidades y de posibilidades realmente existentes en la sociedad. Una sociedad más justa, una teoría del derecho, no se plantean a partir de ensoñaciones o teorías impuestas a la realidad. Una transformación de la sociedad solo es posible en la medida que en la realidad misma existan posibilidades objetivas, históricamente existentes para su transformación. Por ello, Ellacuría afirma:

\section{(c) (i) (ㅇ)}

La Revista Estudios es editada por la Universidad de Costa Rica y se distribuye bajo una Licencia Creative Commons Atribución-NoComercial-CompartirIgual 3.0 Costa Rica. Para más información envíe un mensaje a revistaestudios.eeg@ucr.ac.cr. 
Especial: Profesores de Estudios Generales Investigan

La historización consiste en ver cómo se está realizando, en una circunstancia dada, lo que se afirma abstractamente como un "deber ser" del bien común o de los derechos humanos, y consiste, en segundo lugar, en la posición de aquellas condiciones reales sin las cuales no se puede dar la realización efectiva del bien común y de los derechos humanos. (2001, p.217)

De esta forma, se llega a la realidad con un deber ser que ha sido formulado a partir de las necesidades y posibilidades realmente existentes de la misma. El momento de la historización, o momento práctico de lo teorizado, se convierte en el lugar de verdad, que dirá si las formulaciones hechas sobre la realidad guardan verdad y si se logró desarrollar las potencialidades realmente existentes en la realidad histórica.

Es en esta dirección, que comprendemos las siguientes palabras:

Para Ellacuría, pues, debe denunciarse "la concepción abstracta, ideologizada y ahistórica del derecho", pero también -desde luego- la de los derechos humanos. No será suficiente la perspectiva "el triunfo de la razón sobre la fuerza, sino, más en concreto, desde la defensa del débil contra el fuerte". Lo que propone Ellacuría es aplicar un método de historización de los conceptos, que describe del modo siguiente: a) verificación práctica de la verdad-falsedad, justicia-injusticia, ajuste-desajuste que se da del derecho proclamado; b) constatación de si el derecho proclamado sirve para la seguridad de unos pocos o deja de ser efectivo para los más; c) examen de las condiciones reales para que tengan posibilidades de realidad los propósitos intencionales; d) desideologización de los planteamiento idealistas; e) introducción del elemento tiempo para verificar si planteamientos ideales alcanzan cierto grado aceptable de realidad. (Ribera, 2013, p.39)

Se trata, por tanto, de un proceso negativo, crítico y dialéctico, con momentos de positividad (formulación de normas), pero en un proceso siempre abierto, negativo y de autoconstitución; pues mantiene un sí mismo, como dinamismo real total más que como dinamismo lógico, centrado en el principio de superación (Ellacuría, 1999b, p.435).

\section{(@) $\Theta 0$}

La Revista Estudios es editada por la Universidad de Costa Rica y se distribuye bajo una Licencia Creative Commons Atribución-NoComercial-CompartirIgual 3.0 Costa Rica. Para más información envíe un mensaje a revistaestudios.eeg@ucr.ac.cr. 


\section{Conclusiones}

\section{Especial: Profesores de Estudios Generales Investigan}

Una teoría crítica del derecho vendría a evitar que el bien de cada una de las partes, es decir, el bien común, sea hegemonizado por los dueños de poder económico, y por ende, los que controlan en poder político.

En efecto, las ideologías dominantes viven de una falacia fundamental, la de dar como conceptos reales e históricos, como valores efectivos y operantes, como pautas de acción eficientes, unos conceptos o representaciones, unos valores y unas pautas de acción, que son abstractos y universales. Como abstractos y universales son admitidos por todos; apoyándose de ello, se subsumen realidades que, en su efectividad histórica, son la negación de lo que dicen ser. (Ellacuría, 1976, p.591)

El poner el derecho en la realidad histórica permite corroborar si lo que dice la norma, en cuanto verdad o axioma lógica, se lleva a la práctica realmente; o si, por el contrario, necesita ser ajustada a su realidad o desechada por completo.

La teoría tradicional del derecho vista desde Ellacuría, puede decirse que es producto de la logificación de la inteligencia, pues afirma que en virtud de la racionalidad, estructuración previa de la inteligencia, es que se puede acceder a la historia; o mejor dicho, en virtud del logos conocemos el ser; lo que conlleva a que tanto el ser como la inteligencia se conviertan en realidades cerradas en sí mismas, y, por tanto, incomunicables. Ellacuría, parte de Zubiri, entonces que las personas percibimos el ser en cuanto real, el objeto se manifiesta al consciente, el yo, como parte de la realidad; ahora, en tanto que soy un sujeto pensante, y el ser se me manifiesta como real en cuanto real, empiezo a hurgar en él, a través de mi pensamiento, a buscar y hacer uso de estructuras de análisis que me permitan inteligir con mayor profundidad ese ser que percibo en cuanto real y en cuanto que existe. Esta estructura de pensamiento pone al derecho como el acto racionalteórico-normativo surgido de la praxis, abierto, en permanente ajuste y búsqueda de validez, no como un hecho ajeno o distinto de la praxis, sino, como momento de ella.

\section{(c) (i) (2) (2)}

La Revista Estudios es editada por la Universidad de Costa Rica y se distribuye bajo una Licencia Creative Commons Atribución-NoComercial-CompartirIgual 3.0 Costa Rica. Para más información envíe un mensaje a 


\section{Especial: Profesores de Estudios Generales Investigan}

La teoría crítica del derecho busca construir la civilización del trabajo, y para lograrlo parte de la realidad histórica como el lugar que da verdad y validez al derecho, ya que parte de ella para la construcción de la normativa y regresa a ella para ajustarla o desajustarla y producir la validez in situ.

Si el lugar que da verdad es la realidad histórica, pues en ella se manifiesta la totalidad de la realidad, en esta están contenidas todas las realidades anteriores. El prestar particular atención al movimiento de masas no es fortuito, sino esencia, pues "el sujeto de conocimiento histórico es la clase oprimida misma, cuando combate" (p.6), palabras de Walter Benjamin (1942), que bien suscribiría Ellacuría. Atender, escuchar, teorizar a partir y con los movimientos de masas se convierte esencial para del derecho, escuchar cuáles son sus luchas y sus reclamos, para que así dichos intereses se vean reflejados y asumidos en las normas. Esto no sería más que la génesis de la teoría crítica del derecho.

Distinguir entre sentir e inteligir hace a todas las personas conocedoras de la realidad, dándole vuelta a la lógica del poder, pues devuelve a los vencidos de la historia su papel de protagonistas; pues, si la realidad histórica es la mayor condensación de realidad, y esa realidad es la exclusión y desigualdad, las personas en pobreza se convierten en los verdaderos lugares de verdad de la realidad histórica.

La historización de conceptos se convierte en un método crítico diacrónico y crítico sincrónico, que contribuye a la construcción de una teoría crítica del derecho y que aporta a la construcción de la civilización del trabajo; esto en el tanto que permite historizar por qué los conceptos de la actual teoría tradicional son construcciones producto de la sociedad capitalista; por ejemplo, permite explicar cómo el concepto de propiedad privada en América Latina es una imposición de las personas europeas a las sociedades americanas en la época de la conquista, que tenían un uso colectivo de la misma (Ellacuría, 1976). A su vez,

\section{(c) (i) (2)}

La Revista Estudios es editada por la Universidad de Costa Rica y se distribuye bajo una Licencia Creative Commons Atribución-NoComercial-CompartirIgual 3.0 Costa Rica. Para más información envíe un mensaje a 


\section{Especial: Profesores de Estudios Generales Investigan}

es crítico sincrónico, ya que permite darnos el ajuste-desajuste de la reflexión y teorización de la norma al momento de ser puesta en la realidad histórica.

La historización nos presenta una construcción del derecho no anquilosada, acartonada y estática, sino un derecho vivo y en constante construcción. Proceso que sería parte de una transformación más profunda de la sociedad.

\section{Notas}

${ }^{1}$ Pero más grave que todo ello es que la oferta de humanización y de libertad que hacen los países ricos a los países pobres no es universalizable y, consiguientemente, no es humana, ni siquiera para quienes la ofrecen. El agudo planteamiento de Kant podría aplicarse a este problema: Obra de tal modo, que la máxima de tu voluntad pueda valer siempre, al mismo tiempo, como principio de una legislación universal. Si el comportamiento y aun el ideal de unos pocos no puede convertirse en comportamiento y en realidad de la mayor parte de la humanidad, no puede decirse que ese comportamiento y ese ideal sean morales y, ni siquiera, humanos; cuanto más, si el disfrute de unos pocos se hace a costa de la privación de los más. En nuestro caso, el ideal práctico de la civilización occidental no es universalizable, ni siquiera materialmente, por cuanto no hay recursos materiales en la tierra para que todos los países alcancen el mismo nivel de producción y de consumo, usufructuado hoy por los países llamados ricos, cuya población no alcanza el $25 \%$ de la humanidad (Ellacuría, 2012, p.414).

\section{Bibliografía}

Benjamin, W. (1942). Sobre el concepto de historia. Recuperado Julio 26, 2015, desde http://www.archivochile.com/Ideas_Autores/benjaminw/esc_frank_benjam000 3.pdf

Cascante, L. D. (2003). Voluntad de realidad. El realismo radical. San José: ITAC. Contreras, Ó. (1989a). El otro Kelsen. En Alarcón, V., Correas, Ó., Bobbio, N., Guastini, R., Losano, M., Ruiz, J., ... R. Walter (Edits.), El otro Kelsen. México: Universidad Nacional Autónima de México.

Contreras, Ó. (1989b). Introducción. En Alarcón, V., Correas, Ó., Bobbio, N., Guastini, R., Losano, M., Ruiz, J., ... R. Walter (Edits.), El otro Kelsen. México: Universidad Nacional Autónima de México.

Ellacuría, I. (1976). La historización del concepto de propiedad como principio de desideologización. ECA, 335-336, 587-627.

\section{(a) $(\triangle \odot \odot$}

La Revista Estudios es editada por la Universidad de Costa Rica y se distribuye bajo una Licencia Creative Commons Atribución-NoComercial-CompartirIgual 3.0 Costa Rica. Para más información envíe un mensaje a revistaestudios.eeg@ucr.ac.cr. 
Especial: Profesores de Estudios Generales Investigan

Ellacuría, I. (1987). La cuestión de las masas. ECA, 465, 777-798.

Ellacuría, I. (1989a). El desafío de las mayorías populares. ECA, 493-494, 355364.

Ellacuría, I. (1989b). Superación del reduccionismo idealista en Zubiri. Recuperado Julio 26, 2015, from http://www.uca.edu.sv/centro-documentacion-virtual/wpcontent/uploads/2015/03/C08-c11-03-.pdf

Ellacuría, I. (1991). Función liberadora de la filosofía. En Veinte años de historia en El Salvador (1969-1989) (pp.93-121). San Salvador: UCA Editores.

Ellacuría, I. (1993). Liberación. Revista Latinoamericana de Teología, 1-24.

Ellacuría, I. (1999a). Filosofía de la realidad histórica. San Salvador: UCA.

Ellacuría, I. (1999b). Historización de los derechos humanos desde los pueblos oprimidos y las mayorías populares. En Escritos Filosóficos III. San Salvador: UCA Editores.

Ellacuría, I. (2001). Historización del bien común y de los derecho humanos en una sociedad dividida. En Molina Velazquez, C. (Edit.), Escritos Filosóficos III (Primera). San Salvador.

Ellacuría, I. (2012). Utopía y profetismo desde América Latina. Un ensayo concreto de sotereología histórica. En Senent de Frutos, J. A. (Edit.), La lucha por la justicia. Selección de textos de Ignacio Ellacuría (1969-1989) (pp. 401-459). Bilbao: Universidad de Deusto.

Habermas, J. (1989). La soberanía popular como precedimento. Cuadernos Políticos, 57, 1-32. Recuperado de http://www.bolivare.unam.mx/traducciones/Soberan\%EDa como procedimiento.pdf

Habermas, J. (1997). La lucha por el reconocimiento en el Estado democrático de derecho. Daimon, 15, 25-47. Recuperado de http://revistas.um.es/daimon/article/view/9401/9151

Marx, K. (2003). El 18 Brumario de Luis Bonaparte. Madrid: Fundación Federico 


\section{Especial: Profesores de Estudios Generales Investigan}

Engels.

Ramírez, C. (2002). La inteligencia perdida. De la verdad real a la verdad de la razón: estudio sobre la epistemología y la inteligencia. San José: UNED.

Ribera, R. (2013). Ignacio Ellacuría y la dialéctica. ECA, 68, 35-53. Recuperado de http://www.uca.edu.sv/filosofia/admin/files/1387491285.pdf

Romero Cuevas, J. M. (2013). Ignacion Ellacuria y la necesidad de autorreflexión de la teoría crítica. ECA, 68, 61-65. Recuperado de http://www.uca.edu.sv/upload_w/20/file/732/5-Jose-Romero.pdf

Rousseau, J. (1998). El contrato social. México: Editores mexicanos unidos.

Ruiz Sanz, M. (2002). Sistemas jurídicos y conflictos normativo. Madrid: DYKINSON.

Samour, H. (2001). Filosofía y liberación. ECA, 637-638, 1119-1138. Recuperado de http://www.uca.edu.sv/facultad/chn/c1170/samour1.html

Senent de Frutos, J. A. (2013). Hacia una teoría crítica del derecho. Aportes desde Ignacio Ellacuría. En Sanchez Robio, D. y Senent de Frutos, J. A. (Edits.), Teoría crítica del derecho. Nuevos horizontes (p. 210). México: Universidad Autónoma San Luis Potosí.

Sobrino, J. (2014). Civilización de la pobreza contra civilización de la riqueza para revertir un mundo gravemente enfermo. Papeles de Relación Ecosociales y Cambio Global, 125, 139-150. Recuperado de file://C:/Users/Andres/Dropbox/Artículos

Varios/Civilizacion_de_la_pobreza_contra_civilizacion_de_la_riqueza_J_Sobri no.pdf

Valls Plana, R. (1981). La dialéctica un debate histórico. Barcelona: Montesinos.

Žižek, S. (2008). Bienvenido al desierto de lo real (Tercera). Madrid: Akal.

Žižek, S. (2013). Cómo entender a Lacan. Buenos Aires: Paidós. 